\title{
Central sleep apnea and ventricular arrhythmias in heart failure patients
}

\author{
Márcio Galindo Kiuchi ${ }^{*}$ and Shaojie Chen ${ }^{2}$ \\ ${ }^{1}$ Division of Cardiac Surgery and Artificial Cardiac Stimulation, Department of Medicine, Hospital e Clínica São Gonçalo, Brazil \\ ${ }^{2}$ Department of Cardiology, Shanghai First People's Hospital, Shanghai Jiao Tong University School of Medicine, Shanghai, China
}

The central sleep apnea (CSA) is a chronic respiratory illness branded by fluctuations in respiratory effort, resulting in the pause of respiratory muscle activity and airflow during sleep [1]. Although the prevalence of moderate to severe CSA in the overall population is somewhat, around 3-17\% [2], it is common in patients with atrial fibrillation and stroke and is establish in up to $40 \%$ heart failure (HF) patients [3-8]. It has reliably been shown to be independently related to a poorer prognosis [4-6,8-11]. At present-day, continuous positive airway pressure (CPAP) is the most used treatment for CSA. Both CPAP [12-15] and a newer type of PAP therapy, adaptive servo-ventilation (ASV) [16-19], primarily presented upgrading in CSA and cardiac function in non-randomized studies. On the other hand, their longterm efficacy in dropping morbidity and mortality is still discussed. Certainly, the recently published results of the Adaptive ServoVentilation for Central Sleep Apnea in Systolic Heart Failure Trial (SERVE-HF), a huge randomized multicentre trial evaluating ASV, exposed that ASV was linked with augmented cardiovascular mortality in heart failure patients [New York Heart Association (NYHA) class II (with recent HF hospitalization, III, or IV)] with diminished ejection fraction $(\leq 45 \%)[20,21]$.

Based on these facts, we intend to correlate the ventricular therapies events recorded by the implantable cardiac defibrillator (ICD) in patients with HF and CSA parameters registered by the polysomnography.

We selected 18 patients with with normal renal function, HF, all of them having an ICD and CSA. The study was piloted in agreement with the Helsinki declaration and approved by the ethics committee of our institution. All patients signed the informed consent term before inclusion. This study was conducted at the Hospital e Clínica São Gonçalo, Rio de Janeiro, Brazil. Patients were recruited from January 2016 till June 2016 from the Arrhythmias and Artificial Cardiac Pacing Service of the same hospital. Patients with the combination of the following criteria were consecutively enrolled: (i) age between 18 and 70 years; (ii) ICD implantation for primary prophylaxis to SCD, without ischemia proved by coronary angiography; (iii) central sleep apnea; (iv) glomerular filtration rate estimated by the Chronic Kidney Disease Epidemiology Collaboration (CKD-EPI equation, eGFR [20] $>60 \mathrm{~mL} / \mathrm{min} / 1.73 \mathrm{~m}^{2}$ without microalbuminuria); (v) HF, with functional class defined by NYHA II or III, with reduced left ventricular ejection fraction; and (vi) the capacity to comprehend, and sign the informed consent form and attend the clinical tests. The patients that presented any of the subsequent criteria were excluded: (i) pregnancy; (ii) valvular disease with significant adverse sequelae; (iii) unstable angina, myocardial infarction, transient ischemic attack or stroke within the 6 months before the procedure; (iv) renovascular abnormalities; (v) psychiatric disease; (vi) the inability to be monitored clinically after the procedure; (vii) a known addiction to drugs or alcohol that affects the intellect; (viii) or a serious health condition that, in the investigator opinion's, may adversely affect the safety and/or efficacy of the participant or the study.

The results are expressed as a mean and standard deviation for normally distributed data and as median with interquartile range otherwise. All statistical tests were two-sided. Comparisons between two-paired values were performed with the paired t-test in cases of a Gaussian distribution and by the Wilcoxon test otherwise. Comparisons between more than two-paired values were made by repeatedmeasures analysis of variance or by Kruskal-Wallis analysis of variance as appropriate, complemented by a post-hoc test. Categorical variables were compared with Fisher's exact test. A P-value $<0.05$ was considered significant. Correlations between two variables were performed by Pearson's chi-square test in case of a Gaussian distribution and with the Spearman correlation test otherwise. All statistical analyses were performed using the program Graphpad Prism v 7.0 (Graphpad Software, La Jolla, CA, USA).

The general features of the 18 patients, the chocardiographic parameters, renal function, 24-hour ambulatory blood pressure measurements, ICD therapies and all the polysomnography parameters are displayed in Table 1. We observed significant correlation between anti-tachycardia pacing (ATP) events with apnea-hypopnea index (Pearson: $r=0.9514,95 \%$ Confidence Interval [95\%CI] from 0.8718 to $0.9821, \mathrm{P}<0.0001$, as shown in Figure $1 \mathrm{~A})$, central apnea index (Pearson: $\mathrm{r}=0.9604,95 \% \mathrm{CI}$ from 0.8948 to $0.9854, \mathrm{P}<0.0001$, as shown in Figure $1 \mathrm{~B}$ ), and $4 \%$ oxygen desaturation index (Pearson: $r=0.9099,95 \% \mathrm{CI}$ from 0.7703 to $0.9663, \mathrm{P}<0.0001$, as shown in Figure $1 \mathrm{C}$ ). And also a significant correlation between shock events with apnea-hypopnea index (Pearson: $\mathrm{r}=0.9363$, 95\% CI from 0.8339 to $0.9764, \mathrm{P}<0.0001$, as shown in Figure 1A), central apnea index (Pearson: $r=0.9255$, $95 \% \mathrm{CI}$ from 0.8075 to $0.9723, \mathrm{P}<0.0001$, as shown in Figure $1 \mathrm{~B}$ ),

Correspondence to: Márcio Galindo Kiuchi, MD, MSc, PhD, Division of Cardiac Surgery and Artificial Cardiac Stimulation, Department of Medicine, Hospital e Clínica São Gonçalo, Rua Cel. Moreira César, 138 - Centro, São Gonçalo, Rio de Janeiro 24440-400, Brazil, Tel/Fax: +55 (21) 26047744; E-mail: marciokiuchi@gmail.com

Key words: ventricular arrhythmia, heart disease, implantable cardiac defibrillator, obstructive sleep apnea, sudden cardiac death

Received: August 18, 2016; Accepted: September 14, 2016; Published: September 17, 2016 
Table 1. General features of patients at baseline

\begin{tabular}{|c|c|}
\hline Feature & Central sleep apnea \\
\hline $\mathrm{N}$ & 18 \\
\hline Age, years & $64.4 \pm 16.5$ \\
\hline Body mass index, $\mathrm{kg} / \mathrm{m}^{2}$ & $29.3 \pm 4.1$ \\
\hline Male sex $(\%)$ & $12(67 \%)$ \\
\hline White ethnicity (\%) & $15(83 \%)$ \\
\hline Hypertension & $18(100 \%)$ \\
\hline Type 2 Diabetes Mellitus (\%) & $14(78 \%)$ \\
\hline Coronary artery disease & $15(83 \%)$ \\
\hline Heart failure & $18(100 \%)$ \\
\hline Functional Class NYHA II & $5(28 \%)$ \\
\hline Functional Class NYHA III & $13(72 \%)$ \\
\hline Implantable cardiac defibrillator implanted & $18(100 \%)$ \\
\hline Anti-tachycardia pacing events & $32.9 \pm 11.8$ \\
\hline Anti-tachycardia pacing events & $18(100 \%)$ \\
\hline Shock events & $7.5 \pm 6.0$ \\
\hline Shock events & $12(67 \%)$ \\
\hline Creatinine, $\mathrm{mg} / \mathrm{dL}$ & $0.91 \pm 0.19$ \\
\hline Estimated glomerular filtration rate, $\mathrm{mL} / \mathrm{min} / 1.73 \mathrm{~m}^{2}$ (CKD-EPI) & $105.2 \pm 23.6$ \\
\hline Albumin:creatinine ratio, $\mathrm{mg} / \mathrm{g}$ & $22.4 \pm 6.3$ \\
\hline Mean 24-hour systolic/diastolic ABPM, mmHg & $120.3 \pm 4.8 / 75.0 \pm 3.6$ \\
\hline \multicolumn{2}{|l|}{ Echocardiographic parameters } \\
\hline Left ventricular mass, $\mathrm{g} / \mathrm{m}^{2}$ & $166.7 \pm 23.5$ \\
\hline Left ventricular ejection fraction (Simpson), \% & $29.4 \pm 8.1$ \\
\hline Left ventricular internal dimension at the end of diastole, $\mathrm{mm}$ & $68.0 \pm 6.7$ \\
\hline Left ventricular internal dimension at the end of systole, $\mathrm{mm}$ & $49.8 \pm 3.9$ \\
\hline \multicolumn{2}{|l|}{ Antiarrhythmic agent } \\
\hline Amiodarone & $18(100 \%)$ \\
\hline \multicolumn{2}{|l|}{ Antihypertensive Agents } \\
\hline ACE inhibitors/ARB & $18(100 \%)$ \\
\hline$\beta$-blockers & $18(100 \%)$ \\
\hline Spironolactone & $18(100 \%)$ \\
\hline \multicolumn{2}{|l|}{ Polysomnography parameters } \\
\hline Apnea-hypopnea index, events/hour & $45.2 \pm 18.3$ \\
\hline Central apnea index, events/hour & $33.9 \pm 13.9$ \\
\hline Mixed apnea index, events/hour & $5.4 \pm 4.2$ \\
\hline Hypopnea index, events/hour & $22.5 \pm 10.8$ \\
\hline Obstructive apnea index, events/hour & $3.3 \pm 3.1$ \\
\hline $4 \%$ oxygen desaturation index, events/hour & $51.2 \pm 17.4$ \\
\hline $\mathrm{SpO}_{2}<90 \%$, min & $45.9 \pm 39.1$ \\
\hline Arousal index, events/hour & $42.0 \pm 16.5$ \\
\hline Sleep efficiency, $\%$ & $58.7 \pm 18.4$ \\
\hline Rapid eye movement sleep, $\%$ & $9.7 \pm 4.9$ \\
\hline
\end{tabular}

Values are presented as Mean \pm SD or \%; ABPM, ambulatory blood pressure measurements; ACE, angiotensin-converting enzyme; ARB, angiotensin receptor blocker; N, number of patients.

(A)

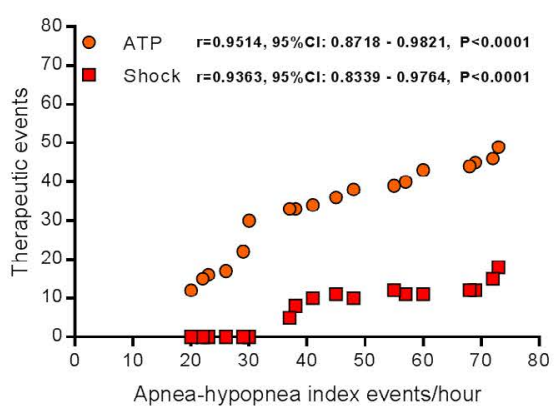

(B)

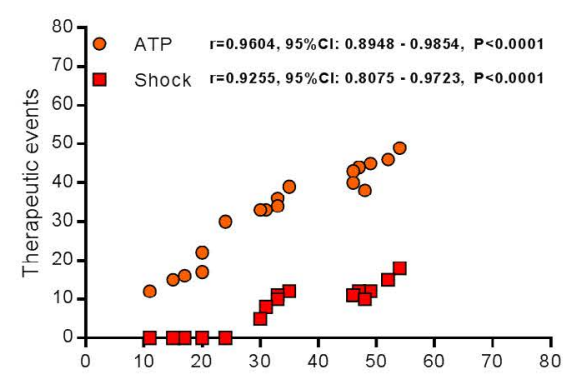

Central apnea index events/hour

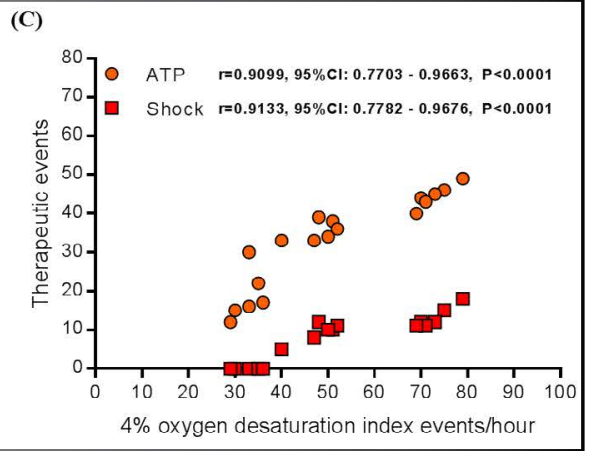

(C)

Figure 1. We observed a significant correlation between anti-tachycardia pacing (ATP) and shock events with apnea-hypopnea index (A), central apnea index (B), and $4 \%$ oxygen desaturation index (C); $95 \% \mathrm{CI}, 95 \%$ confidence interval; $\mathrm{n}=18$. 
and $4 \%$ oxygen desaturation index (Pearson: $r=0.9133$, 95\%CI from 0.7782 to $0.9676, \mathrm{P}<0.0001$, as shown in Figure 1C). Our data show that in patients with CSA and HF that have ICD implanted there was a significant correlation between ICD therapies and apnea-hypopnea index, central apnea index, and $4 \%$ oxygen desaturation index.

\section{Funding} Brazil.

This study was funded by Pacemed (US \$100,000), Rio de Janeiro,

\section{Acknowledgements}

The authors are grateful to all participants included in this study. The authors also thank Pacemed for stimulating the development of this study and for providing technical support.

\section{References}

1. American Academy of Sleep Medicine. International Classification of Sleep Disorders: Diagnostic and Coding Manual, 2nd ed. Westchester, IL; 2005.

2. Peppard PE, Young T, Barnet JH, Palta M, Hagen EW, et al. (2013) Increased prevalence of sleep-disordered breathing in adults. Am J Epidemiol 177: 1006-1014. [Crossref]

3. Paulino A, Damy T, Margarit L, Stoïca M, Deswarte G, et al (2009) Prevalence of sleep-disordered breathing in a 316-patient French cohort of stable congestive heart failure. Arch Cardiovasc Dis 102: 169-175. [Crossref]

4. Oldenburg O, Lamp B, Faber L, Teschler H, Horskotte D, et al. (2007). Sleepdisordered breathing in patients with symptomatic heart failure. Eur J Heart Fail 9: 251-257. [Crossref]

5. Lanfranchi PA, Somers VK, Braghioli A, Corra U, Eleuteri E, et al (2003) Central sleep apnea in left ventricular dysfunction: prevalence and implications for arrhythmic risk. Circulation 107: 727-732.[Crossref]

6. Javaheri S, Parker TJ, Liming JD, Corbett WS, Nishiyama H, et al. (1998) Sleep apnea in 81 ambulatory male patients with stable heart failure. Types and their prevalences, consequences, and presentations. Circulation 97: 2154-2159. [Crossref]

7. Bitter T, Langer C, Vogt J, Lange M, Horstkotte D, et al. (2009) Sleep-disordered breathing in patients with atrial fibrillation and normal systolic left ventricular function. Dtsch Arztebl Int 106: 164-170. [Crossref]

8. Khayat R, Jarjoura D, Porter K, Sow A, Wannemacher J, et al. (2015) Sleep disordered breathing and post-discharge mortality in patients with acute heart failure. Eur Heart $J$ 36: 1463-1469. [Crossref]

9. Jilek C, Krenn M, Sebah D, Obermeier R, Braune A, et al. (2011) Prognostic impact of sleep disordered breathing and its treatment in heart failure: an observational study. Eur J Heart Fail 13: 68-75. [Crossref]

10. Javaheri S, Shukla R, Zeigler H, Wexler L (2007) Central sleep apnea, right ventricular dysfunction, and low diastolic blood pressure are predictors of mortality in systolic heart failure. J Am Coll Cardiol 49: 2028-2034. [Crossref]

11. Khayat R, Abraham W, Patt B, Brinkman V,Wannemacher J, et al. (2012) Central sleep apnea is a predictor of cardiac readmission in hospitalized patients with systolic heart failure. J Card Fail 18: 534-540. [Crossref]

12. Bradley TD, Logan AG, Kimoff RJ, Sériès F, Morrison D, et al. (2005) Continuous positive airway pressure for central sleep apnea and heart failure. N Engl J Med 2005; 353:2025-2033. [Crossref]

13. Javaheri S. (2000) Effects of continuous positive airway pressure on sleep apnea and ventricular irritability in patients with heart failure. Circulation 101:392-397. [Crossref]

14. Sin DD, Logan AG, Fitzgerald FS, Liu PP, Bradley TD. (2000) Effects of continuous positive airway pressure on cardiovascular outcomes in heart failure patients with and without Cheyne-Stokes respiration. Circulation 102:61-66. [Crossref]

15. Naughton MT, Liu PP, Bernard DC, Goldstein RS, Bradley TD. (1995) Treatment of congestive heart failure and Cheyne-Stokes respiration during sleep by continuous positive airway pressure. Am J Respir Crit Care Med 151: 92 97. [Crossref]

16. Oldenburg O, Bitter T, Lehmann R, Korte S, Dimitriadis Z, et al. (2011) Adaptive servoventilation improves cardiac function and respiratory stability. Clin Res Cardiol 100: 107-115. [Crossref]

17. Hastings PC, Vazir A, Meadows GE, Dayer M, Poole-Wilson PA, et al (2010) Adaptive servo-ventilation in heart failure patients with sleep apnea: a real world study. Int $J$ Cardiol 139: 17-24. [Crossref]

18. Kasai T, Usui Y, Yoshioka T, Yanagisawa N, Takata Y, et al. (2010) Effect of flowtriggered adaptive servo-ventilation compared with continuous positive airway pressure in patients with chronic heart failure with coexisting obstructive sleep apnea and Cheyne-Stokes respiration. Circ Heart Fail 3: 140-148. [Crossref]

19. Philippe C, Stoïca-Herman M, Drouot X, Raffestin B, Escourrou P, et al. (2006) Compliance with and effectiveness of adaptive servoventilation versus continuous positive airway pressure in the treatment of Cheyne-Stokes respiration in heart failure over a six-month period. Heart 92: 337-342. [Crossref]

20. Ayas NT, Patil SP, Stanchina M, Malhotra A. (2015) Treatment of central sleep apnea with adaptive servoventilation in chronic heart failure. Am J Respir Crit Care Med 192: 132-133. [Crossref]

21. Cowie MR, Woehrle H, Wegscheider K, Angermann C, d'Ortho MP, et al. (2015) Adaptive servo-ventilation for central sleep apnea in systolic heart failure. $N$ Engl $J$ Med 373: 1095-1105. [Crossref]

Copyright: (C2016 Kiuchi MG. This is an open-access article distributed under the terms of the Creative Commons Attribution License, which permits unrestricted use, distribution, and reproduction in any medium, provided the original author and source are credited. 